\title{
Promoting effect of active carbons on methanol dehydrogenation on sodium carbonate: Hydrogen spillover
}

\author{
Shoujin Su, Michael R. Prairie ${ }^{1}$ and Albert Renken \\ Institute of Chemical Engineering, Swiss Federal Institute of Technology, CH-1015 Lausanne \\ (Switzerland)
}

(Received 1 September 1992, revised manuscript received 13 November 1992)

\begin{abstract}
Methanol dehydrogenation to formaldehyde was conducted in a fixed-bed flow reactor with sodium carbonate catalyst mixed with active carbons or transition metals. The additives promoted the reaction rate at $880-970 \mathrm{~K}$ without modifying formaldehyde selectivity. This effect increases with increasing carbon content in the carbon-carbonate mixture. Activation energy of methanol conversion is the same for the mixture and the carbonate alone. Temperature-programmed desorption experiments showed that hydrogen adsorption resulting from dissociative methanol chemisorption was enhanced by adding active carbon to the carbonate. Also, the carbon facilitates hydrogen desorption in comparison to the carbonate. It is suggested that atomic hydrogen produced on sodium carbonate during methanol dehydrogenation spills over onto active carbons (or metals) and recombines to form hydrogen gas. Hydrogen desorption from sodium carbonate, the rate-determining step, is thus accelerated.
\end{abstract}

Keywords: carbon, formaldehyde, methanol dehydrogenation, sodium carbonate, spillover, transition metals

\section{INTRODUCTION}

Formaldehyde is one of the world's most important chemicals. It is commercially manufactured by the oxidation of methanol in the presence of iron-molybdenum oxides or silver catalysts [1], producing an aqueous solution. Pure formaldehyde is obtained by separation processes such as distillation, which is difficult and expensive due to negative deviations from ideal solution behavior and the formation of azeotropes [2]. Catalytic methanol dehydrogenation to produce water-free formaldehyde presents an attractive alternative to the current method.

For methanol dehydrogenation, sodium carbonate has been found to be an

Correspondence to: Dr. A. Renken, Institute of Chemical Engineering, Swiss Federal Institute of Technology, CH-1015 Lausanne, Switzerland.

'Present address: Sandia National Laboratories, Albuquerque, NM 87185, USA. 
active, selective, and stable catalyst at temperatures from 800 to $1000 \mathrm{~K}$ [3$5]$. Earlier work showed that the principal by-products are carbon monoxide and a small amount of methane [5] (see details in ref. 6). The former is mostly produced from consecutive decomposition of formaldehyde in the gas phase, while the latter is formed in parallel with formaldehyde and carbon monoxide. It was observed that the reaction in the post-catalytic space of a fixed-bed reactor accounted for more than half of the total conversion of methanol [5]. Temperature-programmed desorption and isotopic transient experiments showed that in the dissociative chemisorption of methanol on sodium carbonate, hydrogen is strongly adsorbed, but carbon-containing species are only weakly adsorbed. It has been proposed that the surface reaction results in a strongly absorbed hydrogen atom and a hydroxymethyl free radial [5]. Recombination and desorption of hydrogen limits the overall reaction rate. The free radial species initiates a series of gas-phase chain reactions to form formaldehyde and other products.

Research described in the present paper shows that when active carbons (or transition metals) are mixed mechanically with sodium carbonate, they enhance dramatically the activity of the catalyst without modifying its selectivity. A mechanism of the promoting effect is suggested, which involves hydrogen spillover.

Spillover is a phenomenon which has had such a strong impact on catalysis that two international conferences have been held on this subject $[7,8]$. It refers to the surface diffusion of active species formed on the surfaces of one solid phase (the donor) to another (the acceptor). The spillover species, most often hydrogen, generally exhibit high reactivity and may react with the acceptor [9] or other molecules adsorbed on it [10]. They may also create new types of active sites on the acceptor [11]. The rate of spillover can be accelerated by promotors such as a carboneous deposit [12] or adsorbed water [13]. Although other possible effects should be examined, the following may be indications of spillover [14,15]: (1) The rate of adsorption on a material is promoted by the presence of other components (supported or mixed), but the net adsorption at equilibrium is not largely altered. (2) A gas-solid reaction is accelerated by another solid in contact. (3) The activity of a two-component catalyst exceeds the sum of the individual activities which would be observed if the two components were used separately for the same reaction. More details on spillover phenomenon can be found in the review articles $[7,8,11,14-16]$.

\section{EXPERIMENTAL}

\section{Preparation of the catalysts}

The sodium carbonate $\left(\mathrm{Na}_{2} \mathrm{CO}_{3}\right)$ catalyst was obtained by decomposing sodium bicarbonate (Fluka 71628 ) at $523 \mathrm{~K}$ for $90 \mathrm{~min}$ and then screening it to 
TABLE 1

Catalysts used in the present study ${ }^{a}$

\begin{tabular}{llll}
\hline Catalyst & Composition (wt.-\%) & Catalyst & Composition (wt.-\%) \\
\hline $\mathrm{Na}_{2} \mathrm{CO}_{3}$ & $\mathrm{Na}_{2} \mathrm{CO}_{3}$ & $\mathrm{MgC}$ & $\mathrm{gC}(10)+\mathrm{Na}_{2} \mathrm{CO}_{3}$ \\
$\mathrm{aC}$ & $\mathrm{aC}$ & $\mathrm{MAC}$ & $\mathrm{AC}(10)+\mathrm{Na}_{2} \mathrm{CO}_{3}$ \\
$\mathrm{MaC5}$ & $\mathrm{aC}(5)+\mathrm{Na}_{2} \mathrm{CO}_{3}$ & $\mathrm{Na}_{2} \mathrm{CO}_{3} / \mathrm{aC}^{b}$ & $\mathrm{aC}(20)+\mathrm{Na}_{2} \mathrm{CO}_{3}$ \\
$\mathrm{MaC10}$ & $\mathrm{aC}(10)+\mathrm{Na}_{2} \mathrm{CO}_{3}$ & $\mathrm{aC} / \mathrm{Na}_{2} \mathrm{CO}_{3}{ }^{b}$ & $\mathrm{aC}(20)+\mathrm{Na}_{2} \mathrm{CO}_{3}$ \\
$\mathrm{MaC} 20$ & $\mathrm{aC}(20)+\mathrm{Na}_{2} \mathrm{CO}_{3}$ & $\mathrm{Fe}$ & $\mathrm{Fe}$ \\
$\mathrm{MaC30}$ & $\mathrm{aC}(30)+\mathrm{Na}_{2} \mathrm{CO}_{3}$ & $\mathrm{Ni}$ & $\mathrm{Ni}$ \\
$\mathrm{MaC50}$ & $\mathrm{aC}(50)+\mathrm{Na}_{2} \mathrm{CO}_{3}$ & $\mathrm{MFe}$ & $\mathrm{Fe}(3.5)+\mathrm{Na}_{2} \mathrm{CO}_{3}$ \\
$\mathrm{MaC} 75$ & $\mathrm{aC}(75)+\mathrm{Na}_{2} \mathrm{CO}_{3}$ & $\mathrm{MNi}$ & $\mathrm{Ni}(3.5)+\mathrm{Na}_{2} \mathrm{CO}_{3}$ \\
$\mathrm{MaC97}$ & $\mathrm{aC}(97)+\mathrm{Na}_{2} \mathrm{CO}_{3}$ & & \\
\hline
\end{tabular}

${ }^{a}$ Notation: $\mathrm{aC}$, active carbon powder; $\mathrm{AC}$, active carbon grains; $\mathrm{gC}$, graphite powder.

${ }^{b}$ Not mixed, see text.

$40-80 \mu \mathrm{m}$. Its specific surface area is $1.4 \mathrm{~m}^{2} / \mathrm{g}$ [4]. The activated carbon powders (denoted $\mathrm{aC}$ ) and grains (AC) were used as supplied (Merck 2184 and 2514 respectively). They have different particle sizes (particle diameter $d_{\mathrm{p}}<50$ $\mu \mathrm{m}$ for $70 \%$ weight of the former, $d_{\mathrm{p}}=40-80 \mu \mathrm{m}$ for the latter) but they both exhibit very high surface areas (about $1000 \mathrm{~m}^{2} / \mathrm{g}$ ). Graphite powder $(\mathrm{gC}$ ) was obtained from Fluka (art. 50870) and exhibits low surface area (about $2 \mathrm{~m}^{2}$ / g). The transition metals, iron and nickel, were obtained by reducing the corresponding oxides $\left(\mathrm{Fe}_{2} \mathrm{O}_{3}\right.$ and $\left.\mathrm{NiO}\right)$ in flowing methanol in the reactor. Catalyst mixtures were prepared by mixing mechanically the carbonate and one of these materials, as listed in Table 1.

To test the interactions between $\mathrm{Na}_{2} \mathrm{CO}_{3}$ and $\mathrm{aC}$, the two components $(0.08$ $\mathrm{g} \mathrm{Na}_{2} \mathrm{CO}_{3}, 0.02 \mathrm{~g} \mathrm{aC}$ ) were also separately loaded into the reactor instead of being mixed. The two phases were set apart by a layer $(1 \mathrm{~mm}$ thick $)$ of $0.01 \mathrm{~g}$ carbon fibers (Swiss Silk Bolting Cloth Mfg. Co.). These are denoted as $\mathrm{Na}_{2} \mathrm{CO}_{3} / \mathrm{aC}$ (with $\mathrm{Na}_{2} \mathrm{CO}_{3}$ in front) and $\mathrm{aC} / \mathrm{Na}_{2} \mathrm{CO}_{3}$ (aC in front). Mixing of the two phases during reaction did not occur as observed in an examination of the catalyst bed after $12 \mathrm{~h}$ of use.

\section{Methanol dehydrogenation in the presence of the catalysts}

The catalysts were tested for methanol dehydrogenation in a quartz tubular reactor (internal diameter I.D. $=10 \mathrm{~mm}$ ) at $963 \mathrm{~K}$ under atmospheric pressure. The catalyst, $0.100 \mathrm{~g}$ (except where indicated), was held in place by two layers of quartz wool. The reactor was heated electrically. Temperature variations at different positions in the bed were less than $5 \mathrm{~K}$. Methanol vapor (mole fraction $\left.y_{\mathrm{m}}=0.047\right)$ was continuously fed by bubbling argon $(197 \mathrm{ml} / \mathrm{min}$, given at $273 \mathrm{~K}$ and $101 \mathrm{kPa}(\mathrm{STP})$ ) through a thermostated column containing 
methanol. All the tubing after the reactor was heated to over $390 \mathrm{~K}$ to prevent formaldehyde polymerization. The reaction effluent was analysed with a gas chromatograph (GC) (Hewlett-Packard 5840A), equipped with a thermal conductivity detector.

Temperature-programmed reaction (TPRx) experiments were conducted to compare the temperature dependance of the reaction for $\mathrm{Na}_{2} \mathrm{CO}_{3}$ with that for the mixture $\mathrm{MaC} 10$ (see Table 1 ). The catalyst $(0.05 \mathrm{~g}$ ) was packed in a quartz tube reactor (I.D. $=6 \mathrm{~mm}$ ), heated at $15 \mathrm{~K} / \mathrm{min}$ from $500 \mathrm{~K}$ to $973 \mathrm{~K}$. Reaction conditions were similar to those employed for the isothermal reaction $\left(y_{\mathrm{m}}=0.085\right.$, carrier gas helium $83 \mathrm{ml} / \mathrm{min}$ (STP) ). Methanol concentration in the reaction effluent (mass 32 ) was continuously followed using a mass spectrometer (MS) (Balzers QMG420). Methanol conversion was calculated from intensity of the MS signal, the MS being calibrated with the GC. Since it is difficult to measure formaldehyde concentration with the MS in the presence of methanol, its selectivity was measured with the GC. The procedure was repeated for each sample.

Adsorbed species on $\mathrm{Na}_{2} \mathrm{CO}_{3}, \mathrm{aC}$ and $\mathrm{MaC2O}$ treated by methanol

Temperature-programmed desorption measurements of methanol on the catalysts were conducted using the same apparatus as for the TPRx experiment. The sample, $0.060 \mathrm{~g} \mathrm{aC}, 0.240 \mathrm{~g} \mathrm{Na}_{2} \mathrm{CO}_{3}$ or their mixture $0.300 \mathrm{~g} \mathrm{MaC20}$, was treated with methanol $\left(y_{\mathrm{m}}=0.085\right.$, carrier gas helium $83 \mathrm{ml} / \mathrm{min}$ (STP)) at $623 \mathrm{~K}$ for $60 \mathrm{~min}$, and then cooled at $298 \mathrm{~K}$ in flowing methanol. Prior to desorption, the sample was purged with helium for $40 \mathrm{~min}$. It was then heated in helium at a rate of $15 \mathrm{~K} / \mathrm{min}$ from 298 to $993 \mathrm{~K}$. Important species, $\mathrm{H}_{2}, \mathrm{CH}_{4}$, $\mathrm{CO}, \mathrm{CH}_{2} \mathrm{O}, \mathrm{CH}_{3} \mathrm{OH}$ and $\mathrm{H}_{2} \mathrm{O}$, were followed continuously using the MS.

\section{RESULTS}

\section{Promoting effects of active carbons and metals}

In methanol dehydrogenation at $963 \mathrm{~K}$, the total catalyst mass is kept constant $(0.100 \mathrm{~g}$ ), except for iron and nickel (both $0.0175 \mathrm{~g}$ ). The catalysts deactivated initially and exhibited stable activity after about $10 \mathrm{~h}$. This is shown in Fig. 1 for the catalysts $\mathrm{Na}_{2} \mathrm{CO}_{3}, \mathrm{MaC} 5$ and $\mathrm{MaC20}$ as examples. For all the catalysts, conversions at different times-on-stream $(t=0.5,5$ and $10 \mathrm{~h})$ are given in Fig. 2 and the corresponding selectivities in Fig. 3. As seen from Fig. 2 , the non-selective conversion of methanol obtained with the active carbon $\mathrm{aC}$ is constant with time-on-stream, which is initially much lower but finally higher than that with $\mathrm{Na}_{2} \mathrm{CO}_{3}$. Surprisingly, the mixture with only $5 \%$ aC (MaC5) gives a reaction rate much higher than both $\mathrm{Na}_{2} \mathrm{CO}_{3}$ and $\mathrm{aC}$, independant of the time. In addition, conversion increases with the carbon content 


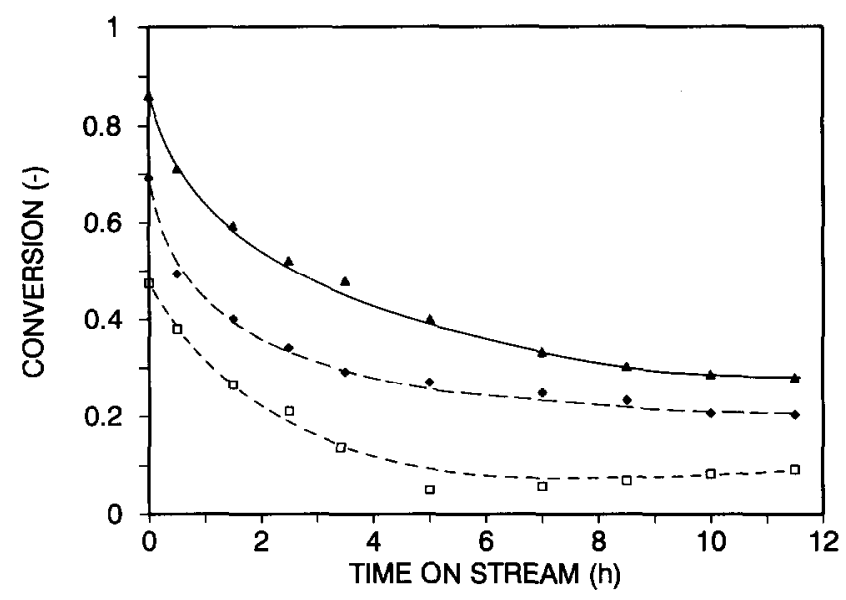

Fig. 1. Deactivation behaviors of several catalysts for methanol dehydrogenation. Conditions: reaction at $963 \mathrm{~K} ; y_{\mathrm{m}}=0.047$; carrier gas argon $(196 \mathrm{ml} / \mathrm{min}, \mathrm{STP})$; total catalyst mass, $0.100 \mathrm{~g}$. Catalyst: ( $\square) \mathrm{Na}_{2} \mathrm{CO}_{3}$; (৬) MaC5; (४) MaC20.

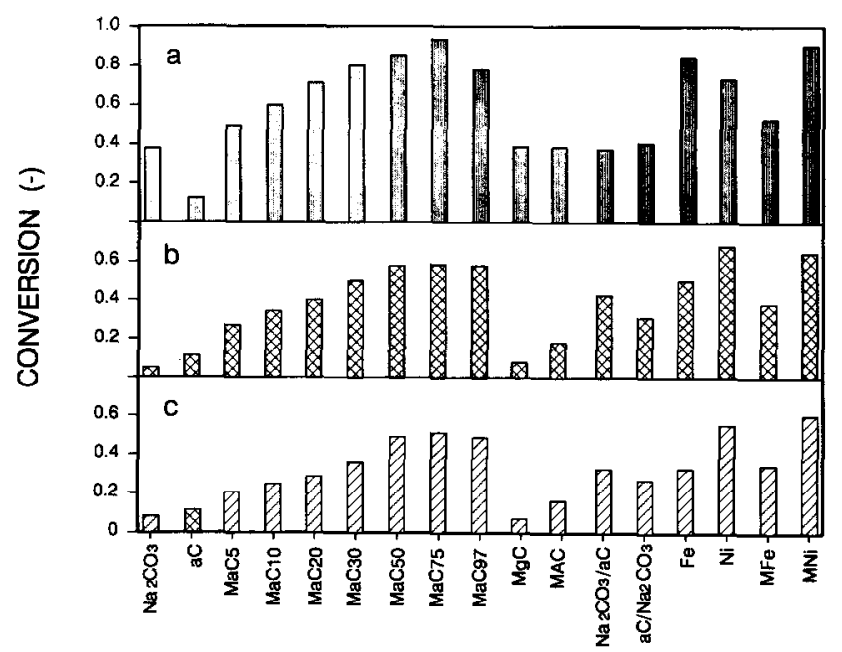

Fig. 2. Activity of different catalysts for methanol dehydrogenation. Same conditions as for Fig. 1 (mass of iron and nickel catalysts: $0.0175 \mathrm{~g}$ ). Time-on-stream: (a) $0.5 \mathrm{~h}$; (b) $5 \mathrm{~h}$; (c) $10 \mathrm{~h}$.

until 75\%, even though the mass of $\mathrm{Na}_{2} \mathrm{CO}_{3}$ in the mixtures decreases with aC content. Even the catalyst $\mathrm{MaC} 97$, which contains only $3 \% \mathrm{Na}_{2} \mathrm{CO}_{3}$, is very active and its deactivation behavior is quite different to that of aC. Interestingly, activity of every mixture exceeds the sum of the contributions of $\mathrm{aC}$ and $\mathrm{Na}_{2} \mathrm{CO}_{3}$ in the mixture. It is evident that synergy exists in the catalyst system $\mathrm{Na}_{2} \mathrm{CO}_{3}-\mathrm{aC}$.

The graphite $\mathrm{gC}$, which is of the same chemical composition as the active carbon aC but exhibits much lower specific surface area, is different from the 


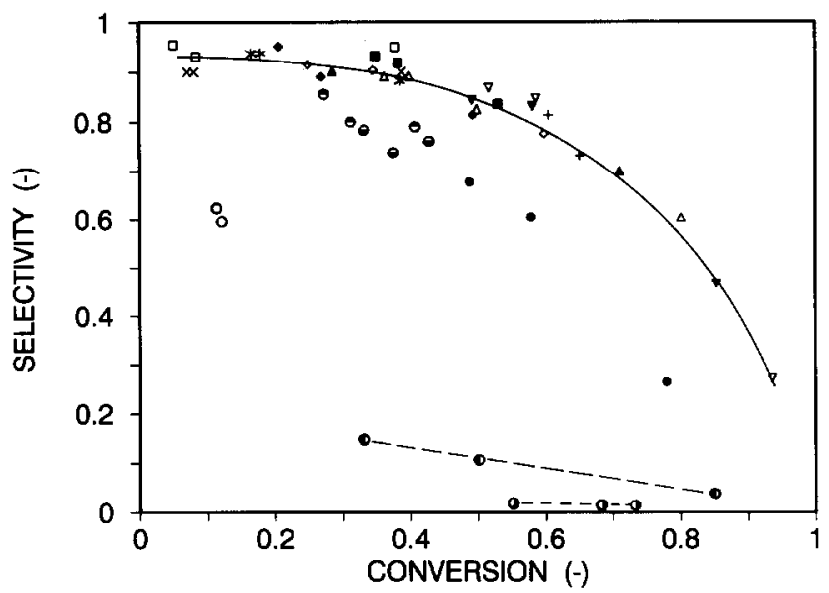

Fig. 3. Selectivity of different catalysts for methanol dehydrogenation. Same experiments as in Fig. 2. Catalyst: ( $\square$ ) $\mathrm{Na}_{2} \mathrm{CO}_{3} ;(\bigcirc) \mathrm{aC} ;(\diamond) \mathrm{MaC}$; ( $\left.\diamond\right) \mathrm{MaC} 10 ;(\Delta) \mathrm{MaC} 20 ;(\Delta) \mathrm{MaC} 30 ;(\nabla)$

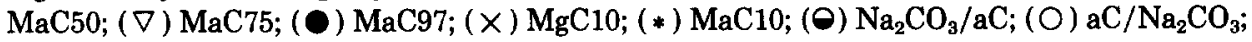
(O) Fe; (O) $\mathrm{Ni}$; (口) $\mathrm{MFe}$; (+) $\mathrm{MNi}$.

active carbon. The mixture $\mathrm{MgC}$ (containing $10 \% \mathrm{gC}$ ) exhibits the same activity as $\mathrm{Na}_{2} \mathrm{CO}_{3}$ alone. This will be discussed later.

In $\mathrm{Na}_{2} \mathrm{CO}_{3} / \mathrm{aC}$ and $\mathrm{aC} / \mathrm{Na}_{2} \mathrm{CO}_{3}, \mathrm{Na}_{2} \mathrm{CO}_{3}$ and $\mathrm{aC}$ were not mixed. With these catalysts, conversions are initially $(t=0.5 \mathrm{~h})$ much lower than the corresponding mixture ( $\mathrm{MaC20})$, and are approximately in the same range as obtained with $\mathrm{Na}_{2} \mathrm{CO}_{3}$. However, conversions eventually arrive at the same level as obtained with $\mathrm{MaC20}(t=10 \mathrm{~h}$ ). Similarly, the active carbon AC (grains) in MAC enhances significantly the reaction rate after $5 \mathrm{~h}$ of reaction. Therefore, it can be concluded that for promoting the reaction, good contact between the carbons and $\mathrm{Na}_{2} \mathrm{CO}_{3}$ is necessary only for fresh catalysts but not for used catalysts.

The methanol dehydrogenation rate also increases when small amounts of transition metals are added to the carbonate (MFe, MNi in Fig. 2). The metals alone are very active for methanol decomposition (mostly to carbon monoxide, see Fig. 3). However, since the quantity of the metals in the mixture is only one fifth of that of the pure metals tested, activities of the mixtures exceed, in general, the sum of the contributions of the two components in MFe and MNi.

What is more interesting is formaldehyde selectivity obtained with the mixtures. As seen from Fig. 3, formaldehyde selectivity is much lower with the active carbon aC than with $\mathrm{Na}_{2} \mathrm{CO}_{3}$, while carbon monoxide is mostly formed with the transition metals as catalysts. However, the selectivities obtained with the mixtures are generally situated on a smooth curve (except for MaC97), independent of time-on-stream. They are the same as for $\mathrm{Na}_{2} \mathrm{CO}_{3}$ alone, when compared at the same conversion level. They vary in the range of $0.80-0.95$ at 
conversions less than 0.6 and decrease steeply to zero at complete conversion due to consecutive decomposition of formaldehyde. Only carbon monoxide and methane are significant by-products, which is the same as for the $\mathrm{Na}_{2} \mathrm{CO}_{3}$ catalyst [5]. These observations suggest that the main products are formed through reactions on $\mathrm{Na}_{2} \mathrm{CO}_{3}$ in the mixtures, and that the additives promote only the rate-limiting step of the reaction on $\mathrm{Na}_{2} \mathrm{CO}_{3}$.

Low selectivities of the active carbons and the metals alone do not result in low selectivities of the mixtures. This indicates that non-selective decomposition of methanol on $\mathrm{aC}, \mathrm{Fe}$ and $\mathrm{Ni}$ in the mixtures is not significant when compared to the reaction on $\mathrm{Na}_{2} \mathrm{CO}_{3}$. The relatively low selectivity seen with $\mathrm{MaC} 97$ is probably due to its extremely low $\mathrm{Na}_{2} \mathrm{CO}_{3}$ content and the significant decomposition of both methanol and formaldehyde on the active carbon.

Temperature dependance of the reaction on the mixture $\mathrm{MaC10}$

Results of TPRx experiments are shown in Fig. 4 in the form of Arrhenius plots:

$\ln k=\ln \left[-\frac{1}{\tau} \ln (1-X)\right]=\ln A--\frac{E_{\mathrm{a}}}{R T}$

where $X$ is methanol conversion, $E_{\mathrm{a}}$ is the activation energy, $k$ and $A$ are the reaction rate constant and frequency factor, respectively, and $\tau$ is space time. A first-order reaction is assumed. The samples were used in one TPRx cycle and their activities were stable.

In the entire temperature range, the reaction rate with the mixture $\mathrm{MaC10}$ is always higher than with $\mathrm{Na}_{2} \mathrm{CO}_{3}$. This is also true for fresh catalysts (not

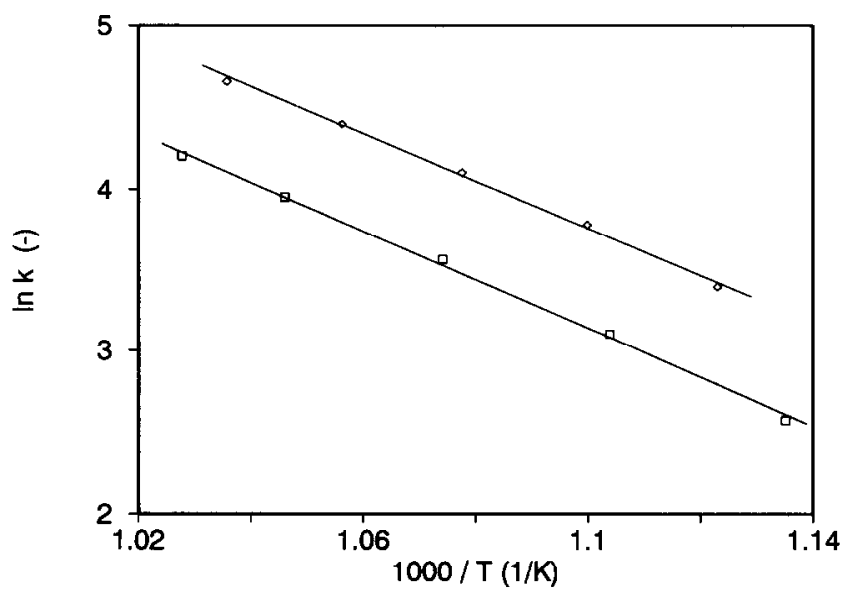

Fig. 4. Arrhenius plots for methanol dehydrogenation into formaldehyde on $\mathrm{Na}_{2} \mathrm{CO}_{3}$ and $\mathrm{MaC} 10$. Conditions: $50 \mathrm{mg}$ catalyst (used in one TPRx cycle), $y_{\mathrm{m}}=0.087$, carrier gas helium $(83 \mathrm{ml} / \mathrm{min}$, STP). ( $\square$ ) $\mathrm{Na}_{2} \mathrm{CO}_{3}$; ( $\left.\diamond\right) \mathrm{MaC} 10$. 
shown). The apparent activation energies in the range of $880-970 \mathrm{~K}$ are practically the same (about $130 \mathrm{~kJ} / \mathrm{mol}$ ) for $\mathrm{Na}_{2} \mathrm{CO}_{3}$ and $\mathrm{MaC10}$ catalysts. It is important to note that formaldehyde selectivity was also found to be the same in the entire temperature range for the two catalysts [6].

Adsorbed species on $\mathrm{Na}_{2} \mathrm{CO}_{3}, a \mathrm{C}$ and their mixture $\mathrm{MaC2O}$

During temperature-programmed desorption experiments preceded by methanol treatment of the three materials at $623 \mathrm{~K}$, methanol is partially desorbed intact, as shown in Fig. 5a. Methanol desorbs from $\mathrm{Na}_{2} \mathrm{CO}_{3}$ between 300 and $750 \mathrm{~K}$ and from MaC20 between 300 and $600 \mathrm{~K}$. Since the boiling point of methanol is $338 \mathrm{~K}$, it is likely that much of this desorbed methanol was chemisorbed on the catalyst. This chemisorbed methanol is probably important in methanol dehydrogenation. However, it is difficult to compare the desorption results for $\mathrm{Na}_{2} \mathrm{CO}_{3}$ and $\mathrm{MaC} 20$ because of the interference of physisorption on $\mathrm{MaC} 20$. On the active carbon aC alone, there is little chemisorption of methanol above $400 \mathrm{~K}$, though physisorption is significant. This may explain the low selectivity of the active carbon (non-catalytic thermal reaction).

Heating the methanol-pretreated catalysts above $600 \mathrm{~K}$ produces a spectrum of decomposition products, including $\mathrm{CO}, \mathrm{H}_{2}, \mathrm{CH}_{2} \mathrm{O}, \mathrm{CH}_{4}$ and $\mathrm{H}_{2} \mathrm{O}$ [6]. However, $\mathrm{CH}_{2} \mathrm{O}, \mathrm{CH}_{4}$ and $\mathrm{H}_{2} \mathrm{O}$ were observed in trace amounts, while significant

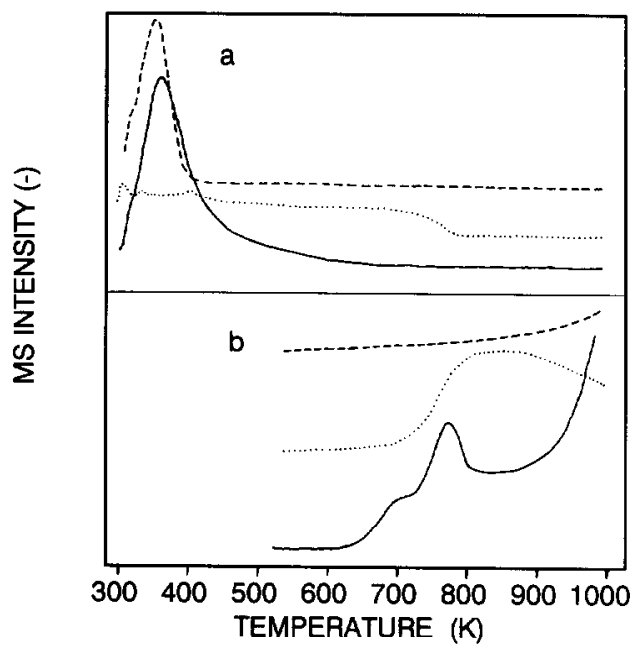

Fig. 5. Temperature-programmed desorption of methanol on $\mathrm{aC}, \mathrm{Na}_{2} \mathrm{CO}_{3}$ and $\mathrm{MaC} 20$. Sample used once in a temperature-programmed desorption cycle. Methanol dosing: at $623 \mathrm{~K}$ for $60 \mathrm{~min}$. Purging by helium at $298 \mathrm{~K}$ for $40 \mathrm{~min}$. Desorption: heated at $15 \mathrm{~K} / \mathrm{min}$, carrier gas helium (30 $\mathrm{ml} / \mathrm{min}, \mathrm{STP}$ ). (a) Methanol species (mass 32): (--) $0.06 \mathrm{~g} \mathrm{aC}(\times 1) ;(\cdots)) 0.24 \mathrm{~g} \mathrm{Na}_{2} \mathrm{CO}_{3}$ $(\times 20) ;(-) 0.30 \mathrm{~g} \mathrm{MaC20}(\times 1)$. (b) Hydrogen species (mass 2$):(--) 0.06 \mathrm{~g} \mathrm{aC}(\times 7) ;(\cdots \cdots)$ $0.24 \mathrm{~g} \mathrm{Na}_{2} \mathrm{CO}_{3}(\times 7) ;(-) 0.30 \mathrm{~g} \mathrm{MaC} 20(\times 1)$. 
carbon monoxide desorption was observed only on the active carbon over 900 $\mathrm{K}$ and the adsorption is evidently too strong to participate in methanol dehydrogenation.

Hydrogen was the only species that desorbed significantly above $600 \mathrm{~K}$ (Fig. $5 \mathrm{~b}$ ). This suggests that during methanol treatment of the sample at $663 \mathrm{~K}$, surface reactions occurred, producing adsorbed hydrogen and easily desorbed carbon-containing species. This is in agreement with other observations mentioned previously. From the desorption spectra shown in Fig. 5b, the following suggestions can be made:

(1) Strong chemisorption of hydrogen occurs on MaC20; the hydrogen desorbs above $800 \mathrm{~K}$. This strong adsorption may not be involved in methanol dehydrogenation and is due to decomposition of hydrogen surface compounds on carbons, as reported in ref. 17.

(2) The chemisorbed hydrogen on $\mathrm{MaC} 20$ that desorbed between 650 and $800 \mathrm{~K}$ may be involved in catalytic methanol dehydrogenation. The desorption occurs at a lower temperature than that from $\mathrm{Na}_{2} \mathrm{CO}_{3}$. The presence of two desorption peaks indicates two types of active sites on the mixture.

(3) The hydrogen chemisorbed on $\mathrm{MaC} 20$ significantly exceeds that adsorbed on either $\mathrm{aC}$ or $\mathrm{Na}_{2} \mathrm{CO}_{3}$ alone. This indicates that hydrogen transport has probably occurred between the two phases during the exposure to methanol. The active carbon alone does not decompose methanol remarkably, but its surface area is much higher than that of $\mathrm{Na}_{2} \mathrm{CO}_{3}$. This indicates that during methanol exposure, hydrogen is produced on $\mathrm{Na}_{2} \mathrm{CO}_{3}$ and spills over onto aC.

\section{DISCUSSION}

The active carbons and the transition metals dramatically increase the activity of sodium carbonate for methanol dehydrogenation when they are mixed with the carbonate. They do not significantly alter the product distributions. This effect was observed over the entire temperature range that was tested. Rate enhancement occurs when active carbons are used, but graphite is inert. Direct contact between the two phases is important for fresh catalysts. The quantity of chemisorbed hydrogen resulting from methanol chemisorption on the carbon-carbonate mixture exceeds significantly that on the two components alone, and hydrogen desorption from the mixture takes place at lower temperatures. Therefore, there must be a synergetic effect between $\mathrm{Na}_{2} \mathrm{CO}_{3}$ and $\mathrm{aC}$ in relation to methanol dehydrogenation.

As mentioned previously, the main reaction of methanol dehydrogenation on $\mathrm{Na}_{2} \mathrm{CO}_{3}$ proceeds through $\mathrm{H}-\mathrm{CH}_{2} \mathrm{OH}$ bond cleavage to form ${ }^{\circ} \mathrm{CH}_{2} \mathrm{OH}$ free radicals and leave hydrogen on the surface [5]. The hydrogen is strongly adsorbed and its recombination and desorption determine the reaction rate. As a result, the splitting of methanol molecules on $\mathrm{Na}_{2} \mathrm{CO}_{3}$ leads to the accumu- 
lation of hydrogen on the surface, and eventually the overall reaction is inhibited.

Active carbons exhibit high surface areas and good ability to adsorb atomic hydrogen, while iron and nickel are typical catalysts for dehydrogenation. The latter have the same effect for methanol dehydrogenation as the former when mixed with sodium carbonate. This supports the hypothesis that removing hydrogen from sodium carbonate is involved in the promoting effect of the additives.

From these observations, the mechanism seems to involve hydrogen spillover from $\mathrm{Na}_{2} \mathrm{CO}_{3}$ to active carbons (or the transition metals) in methanol dehydrogenation catalysed by the mixtures. This accelerates the reaction by decreasing the accumulation of ${ }^{\circ} \mathrm{H}$ on $\mathrm{Na}_{2} \mathrm{CO}_{3}$, as described by the following model:

$\mathrm{CH}_{3} \mathrm{OH}_{\mathrm{g}} \rightleftharpoons \mathrm{CH}_{3} \mathrm{OH}_{\mathrm{s}}$

$\mathrm{CH}_{3} \mathrm{OH}_{\mathrm{s}} \rightleftharpoons \cdot \mathrm{H}_{\mathrm{s}}+{ }^{-} \mathrm{CH}_{2} \mathrm{OH}_{\mathrm{g}}$

$\mathrm{CH}_{3} \mathrm{OH}_{\mathrm{s}} \rightleftharpoons \mathrm{CH}_{3} \mathrm{O}_{\mathrm{s}}^{*}+\cdot \cdot \mathrm{H}_{\mathrm{s}}$

$\mathrm{CH}_{3} \mathrm{O}_{\mathrm{s}}^{*} \rightarrow \mathrm{CO}_{\mathrm{g}}+\frac{3}{2} \mathrm{H}_{2 \mathrm{~g}}$

$\mathrm{CH}_{3} \mathrm{O}_{\mathrm{g}} \rightarrow \mathrm{CH}_{2} \mathrm{O}_{\mathrm{g}}+\frac{1}{2} \mathrm{H}_{2 \mathrm{~g}}$

$\cdot \mathrm{H}_{\mathrm{s}}+\mathrm{CH}_{3} \mathrm{OH}_{\mathrm{s}} \rightarrow \mathrm{H}_{2 \mathrm{~g}}+{ }^{\circ} \mathrm{CH}_{2} \mathrm{OH}_{\mathrm{g}}$

$\cdot \mathrm{H}_{\mathrm{s}}+\cdot \mathrm{H}_{\mathrm{s}} \rightarrow \mathrm{H}_{2 \mathrm{~g}}$

$\cdot \mathrm{H}_{\mathrm{s}} \rightleftharpoons \cdot \mathrm{H}_{\mathrm{c}}$

$\cdot \mathrm{H}_{\mathrm{c}}+{ }^{\cdot} \mathrm{H}_{\mathrm{c}} \rightarrow \mathrm{H}_{2 \mathrm{~g}}$

$\mathrm{CH}_{3} \mathrm{OH}_{\mathrm{g}} \rightleftharpoons \mathrm{CH}_{3} \mathrm{OH}_{\mathrm{c}}$

$\mathrm{CH}_{3} \mathrm{OH}_{\mathrm{c}} \rightarrow$ non-selective reactions

(formation of $\mathrm{CO}, \mathrm{CH}_{2} \mathrm{O}_{\mathrm{g}}$ and etc.)

$\cdot \mathrm{CH}_{2} \mathrm{OH}_{\mathrm{g}} \rightarrow$ further gas phase reactions

(formation of $\mathrm{CH}_{2} \mathrm{O}, \mathrm{H}_{2}, \mathrm{CO}$ and $\mathrm{CH}_{4}$ )

where ' $\mathrm{s}$ ' and ' ' indicate sodium carbonate surface and gas phase, and '' refers to species on the carbon (or metal) surface.

Since the catalyst with only $3 \% \mathrm{Na}_{2} \mathrm{CO}_{3}$ is still very active (Fig. 2 ), reactions (3-6) must be very fast. Reaction (7) is thought to be insignificant compared to (3). Reaction (8) limits the overall reaction on sodium carbonate. Reaction (9) is a surface diffusion process (spillover). Reactions (9) and (10) take place only when carbons or transition metals are in contact with $\mathrm{Na}_{2} \mathrm{CO}_{3}$. In this case, hydrogen migrates from $\mathrm{Na}_{2} \mathrm{CO}_{3}$ onto carbon or metal atoms and 
recombines to form hydrogen gas. This accelerates reaction (8), the rate-determining step. Reaction (12) represents all the reactions on carbon surfaces which are not selective for formaldehyde. The radical ${ }^{\circ} \mathrm{CH}_{2} \mathrm{OH}_{\mathrm{g}}$ leads to further gas phase reactions [reaction (13) ] producing $\mathrm{CH}_{2} \mathrm{O}, \mathrm{CO}$ and $\mathrm{CH}_{4}$ as discussed elsewhere [5].

Hydrogen spillover from the carbonate to the graphite $\mathrm{gC}$ in $\mathrm{MgC}$ probably occurs, but this does not accelerate the reaction rate since its ability to accept hydrogen is very low because of its low surface area (ca. $2 \mathrm{~m}^{3} / \mathrm{g}$ compared to ca. $1000 \mathrm{~m}^{2} / \mathrm{g}$ for active carbons).

Active carbon in the mixtures promotes the reaction rate but does not change the selectivity. From the above model, the acceleration by the active carbon does not influence the relative rates of reactions (3) and (4), which determine the selectivities to formaldehyde and carbon monoxide on the surface.

Poor contact hinders the initial activity of the catalysts $\mathrm{Na}_{2} \mathrm{CO}_{3} / \mathrm{aC}, \mathrm{aC} /$ $\mathrm{Na}_{2} \mathrm{CO}_{3}$ and MAC10. However, a promoting effect was seen in these catalysts after a certain time-on-stream. In fact, a carbonaceous deposit on the catalyst surfaces was formed during the reaction, whose quantity reached $5 \%$ of the catalyst after 6 hours-on-stream [6]. Therefore, hydrogen spillover in these systems is probably facilitated by the formation of coke at the interface, as suggested by Boudart et al. [12].

We conclude that active carbons are suitable supports for sodium carbonate catalyst, not only because of their thermal and mechanical properties, but also because of the synergy between the supports and the catalyst. Carbon-supported catalysts doped with nickel or iron, for example, may be promising for practical applications.

\section{ACKNOWLEDGEMENTS}

We are grateful to the Swiss National Foundation for financial support.

\section{REFERENCES}

1 J. Catalàn Cancho, A.M. Estevez Sànchez, A. Fernandez Tena and M.C. Màrquez Moreno, Chem. Bio. Eng. Quarterly, 3 (1-2) (1989) 51.

2 S.J. Green and R.E. Vener, Ind. Eng. Chem., 47 (1) (1955) 103.

3 A. Meyer and A. Renken, in M.J. Phillips and M. Ternan (Editors), Proc. 9th Int. Cong. Catal., Calgary, Canada, 1988, The Chemical Institute of Canada, Ottawa, 1988, Vol. 4, p. 1898.

4 A. Meyer and A. Renken, Chem. Eng. Technol., 13 (1990) 145.

5 S. Su, M.R. Prairie and A. Renken, Appl. Catal. A, 91 (1992) 131.

6 S. Su, Ph.D. Dissertation, No. 970, Swiss Federal Institute of Technology, Lausanne, 1991.

7 G.M. Pajonk, S.J. Teichner and J.E. Germain (Editors), Spillover of Adsorbed Species, Elsevier, Amsterdam, 1983. 
8 K.H. Steinberg (Editor), Proc. 2nd Int. Conf. on Spillover, Karl Marx University, Leipzig, 1989.

9 A. Tomota and Y. Tamai, J. Catal., 27 (1972) 293.

10 K.H. Steinberg, U. Mroczek and F. Roessner, in K.H. Steinberg (Editor), Proc. 2nd Int. Conf. on Spillover, Karl Marx University, Leipzig, 1989, p. 50.

11 S.J. Teichner, Appl. Catal., 62 (1990) 1.

12 M. Boudart, A.W. Aldag and M.A. Vannice, J. Catal., 18 (1970) 46.

13 G.C. Bond and T. Mallat, J. Chem. Soc., Farad. Trans. 1, 77 (1981) 1743.

14 P.A. Sermon and G.C. Bond, Catal. Rev., 8 (1974) 211.

15 B.K. Hodnett and B. Delmon in L. Červený (Editor), Catalytic Hydrogenation (Studies in Surface Science and Catalysis, Vol. 27), Elsevier, Amsterdam, 1986, p. 53.

16 D.A. Dowden, in Roy. Chem. Soc. (Editors), Specialist Periodic Report Catalysis, Vol. 3, London, 1980, p. 136.

17 J.J. Cookson, in P.N. Chermisinoff and F. Ellerbosch (Editors), Carbon Adsorption Handbook, Ann Arbor Science Publishers, Ann Arbor, MI, 1978. 